\title{
Temperature Discontinuity Caused by Relocation of Meteorological Stations in Taiwan
}

\author{
Chih-wen Hung \\ Department of Geography, National Taiwan Normal University, Taipei, Taiwan, ROC \\ Received 30 November 2007, accepted 11 July 2008
}

\begin{abstract}
With global warming upon us, it has become increasingly important to identify the extent of this warming trend and in doing so be able to rank mean temperature changes in particular seasons and years. This requires a need for homogeneous climate data, which do not reflect individual anomalies in instruments, station locations or local environments (urbanization). Accurate homogeneous long-term meteorological data helps show how temperature variations have truly occurred in the climate. Many possible factors contribute to artificial abrupt changes or sharp discontinuities in long time series data, such as the impact of station relocation, changes in observational schedules and instrumentation. Homogeneity adjustments of in situ climate data are very important processes for preparing observational data to be used in further analysis and research. Users require a well-documented history of stations to make appropriate homogeneity adjustments because precise historical background records of stations can provide researchers with knowledge of when artificial discontinuity has occurred and its causes. Without such detailed historical data for each meteorological station, abrupt changes are difficult to interpret. Unfortunately, no homogeneity adjustments for temperature records have been conducted previously in Taiwan, and present available sources of the history of Taiwan's meteorological stations exhibit inconsistencies. In this study, information pertaining to station history, especially relocation records, is provided. This information is essential for analysis of continuous time series data for temperature and climate warming studies. Temperature data from several stations is given in this study to show how artificial discontinuity occurs due to station relocation. Although there is no homogeneous adjusted climate data provided in this preliminary work, the summarizing of information regarding station relocations should be of assistance to future data users wanting to determine whether or not abrupt changes in climate data are artificial.
\end{abstract}

Key words: Warming trend in Taiwan, Temperature discontinuity, History of meteorological stations in Taiwan, Taiwan climate data, Homogeneity adjustments

Citation: Hung, C.-w., 2009: Temperature discontinuity caused by relocation of meteorological stations in Taiwan. Terr. Atmos. Ocean. Sci., 20, 607-617, doi: 10.3319/TAO.2008.07.11.01(A)

\section{INTRODUCTION}

With global warming upon us, it has become increasingly important to identify the extent of this warming trend and to also be able to rank mean temperature changes in particular seasons and years. This requires homogeneous climate data that do not reflect individual anomalies in instruments, station locations or local environments (urbanization). Unfortunately, different algorithms for homogeneity adjustments on original metadata give different results; for example, the change in algorithms of the US Historical Climatology Network (USHCN), which includes more than one

\footnotetext{
* Corresponding author

E-mail: cwhung@ntnu.edu.tw
}

thousand weather stations for the continental US (see the USHCN data website at: http://www.ncdc.noaa.gov/oa/ climate/research/ushcn/ for details). Beginning in 2007, improved correction schemes (Menne and Williams 2005; Menne and Williams 2009) have been applied to the USHCN by NOAA's National Climate Data Center (NCDC). This change has had no significant impact on the long-term temperature trend, but has resulted in changes for the annual ranking of some years. Although different versions of corrections produce different adjusted datasets, homogeneity adjustment is still required to prevent pronounced discontinuity; i.e., abstractions that are not real variations in weather and climate. 
There are many possible factors that can contribute to artificially abrupt changes in long-time series climate data, such as station relocation effects, changes in observational schedules and instrumentation (Karl et al. 1986; Karl and Williams 1987; Quayle et al. 1991). Homogeneity adjustments of these in situ climate data are very important processes in readying observational data for further analysis and research. A review provided by Peterson et al. (1998) has summarized several methodologies for homogeneity testing and progress made in several countries/regions (Australia, Austria, Canada, Finland, New Zealand and Pacific Islands, Norway, Sweden, and USA). In addition to these local datasets, efforts toward making homogeneity adjustments on global data are discussed.

Abrupt changes and decadal variations in Taiwan's climate have been studied in many aspects. Unfortunately, no homogeneity adjustments have been done for climate data in Taiwan before these studies were published. Although there are methods to help in detecting undocumented change points for climate data (Menne and Williams 2005), it is necessary for users to realize what the documented change time is for station relocations, and changes in observational schedules and instrumentation before using such data in research. In the present work, the history of station relocation is our main focus. This information is essential for analysis of continuous time series data for temperature and climate warming studies. Temperature data is used here to show how pronounced artificial discontinuity is due to station relocation as temperature is a less sensitive variable compared to precipitation and wind. If temperature does exhibit an unexpectedly abrupt change due to station relocation then it is highly possible that other variables will have also been influenced.

Precise historical background records of stations can indicate when artificial discontinuity has occurred and its cause (Peterson et al. 1998). Without detailed historical background checks for each meteorological observatory (conventional weather stations; hereafter stations), abrupt changes are difficult to interpret. In Taiwan, old weather records can be traced back to the Ching Dynasty (1885). However, the Japanese established a more well organized weather observational network after 1895. Commencement of most stations currently operated by the Central Weather Bureau (hereafter CWB) in Taiwan occurred during the Japanese colonial era (hereafter, the JP era). Background information for some stations in this period was lost after World War II (hereafter WWII) or remains erroneous. The information (year of commencement) listed in the "Summary report of meteorological data (Taiwan), Volume VI 1991 2000" (CWB 2002), the CWB website (http://www .cwb.gov.tw) and Hung (2007) present differences. Station commencement years and first recorded data are incongruous in the CWB database. For example, the first collection date for Keelung's data currently remaining in the CWB database is 1930 or earlier (different versions), while the commencement date for this station from CWB records and website is 1946. Similar situations exist at other stations. Careful review of the history of Taiwan's stations leads to more inconsistencies and much confusion. Therefore, the objective of this study is to summarize station backgrounds in Taiwan, and temperature discontinuities arising from station relocations.

All stations and data reviewed in this study are from the CWB except temperature data from Song-shan airport, which was provided by the Civil Aeronautics Administration in Taiwan. Locations of CWB stations are shown in Fig. 1, and their corrected information is provided in Tables 1 and 2. English spelling for these stations is from the CWB, which can be found on its website and in summary reports. In general, the 5-digit weather station codes are used except for special situation when a 6-digit code (one extra last digit) is necessary to distinguish parallel observation periods or new/old observational sites. In our study, the traditional 5-digit code and additional single digit final code are separated by a dash. This may be absent in some CWB data formats. More detail of the historical background of sites can be found in Hung (2007) (Chinese only). The annual mean of daily temperature, daily maximum temperature (hereafter Tmax) and daily minimum temperature (hereafter Tmin) are the major variables discussed in this study.

The remainder of the paper is organized as follows: Meteorological stations in Taiwan without serious relocation problems are described in section 2 while others with permanent or tentative relocations are summarized in section 3 along with their temperature discontinuities. Our conclusions and discussion regarding other factors contributing to artificially abrupt changes in the meteorological data are provided in section 4 .

\section{STATIONS WITHOUT SERIOUS RELOCATION PROBLEMS}

Throughout Taiwan's meteorological history, some stations have maintained the same codes and names whilst their locations have changed. This was especially true in the late $19^{\text {th }}$ and early $20^{\text {th }}$ century. However, once permanent observation sites were decided, most of Taiwan's observational stations have not had serious discontinuity problems pertaining to relocation issues. For these stations, observational sites have essentially not changed though urbanization may have affected their immediate environments. The stations in this category are: Alishan (No. 46753), Anpu (No. 46691), Chengkung (No. 46761), Chiayi (No. 46748), Chutzehu (No. 46693), Hengchun (No. 46759), Hualien (No. 46699), Ilan (No. 46708), Jiyuehtan (No. 46765), Kinmen (No. 46711), Lanyu (No. 46762), Mazu (No. 46799), Pengchiayu (No. 46695), Penghu (No. 46735), Suao (No. 46706), Taitung (No. 46766), Tanshui (No. 46690), Tawu (No. 46754), 
Tungchitao (No. 46730), Wuchi (No. 46777), and Yushan (No. 46755). As mentioned in the introduction, according to the CWB, commencement years for some of the above stations are incongruous with the first data collected at these sites, a situation requiring revision (see Table 1). Descriptions of specific stations are provided below.

\subsection{Observations by Lighthouse Workers}

Some meteorological observations in Taiwan were first conducted by lighthouse workers. Such data were then added to the CWB database. For example, the official commencement of meteorological observatories in Pengchiayu (No. 46695; also known as Agincourt) and Hualien (No. 46699) are 1936 and 1921, respectively, while lighthouse observations have existed in the time series data of the CWB since 1910 at both sites. The locations of lighthouse and meteorological observations are almost the same for both stations resulting in the weather data being grouped under respective observatories (note: differences in data quality exists).

\subsection{Questionable Commencement Years and Observational Locations}

Questions regarding commencement years and observational locations for some stations in Taiwan remain un- resolved. For example, the actual commencement date for observations at Anpu (No. 46691) and Chutzehu (No. 46691) are still unknown. Weather data remaining in the CWB records for these two stations commenced on 1943.1.1, while most other CWB sources give the commencement year of both stations as 1937. Accordingly, a retired CWB worker claims observations at Anpu and Chutzehu began later than 1942 (Hung 2007). Another questionable record is for Jiyuehtan (No. 46765) at Sun-moon Lake, Central Taiwan. This station is located on a hill. The main purpose of establishing the station during the JP era was to observe the vertical profile of wind at $\sim 1000 \mathrm{~m}$ for aviation. Consequently, the most important building at this station was the wind tower. Other meteorological variables for this location seem not to have been recorded at the tower location during the JP era. However, records at the CWB indicate that observations were made of all meteorological variables at the location of the wind tower when an official meteorological observatory was finally constructed in December 1951.The exact location of observations prior to this time is unclear.

\subsection{Questionable Temperature Deviations between Tanshui and Taipei}

Tanshui (No. 46690) (or sometimes Tamsui) is an old harbor town in northern Taiwan, which is now an outer

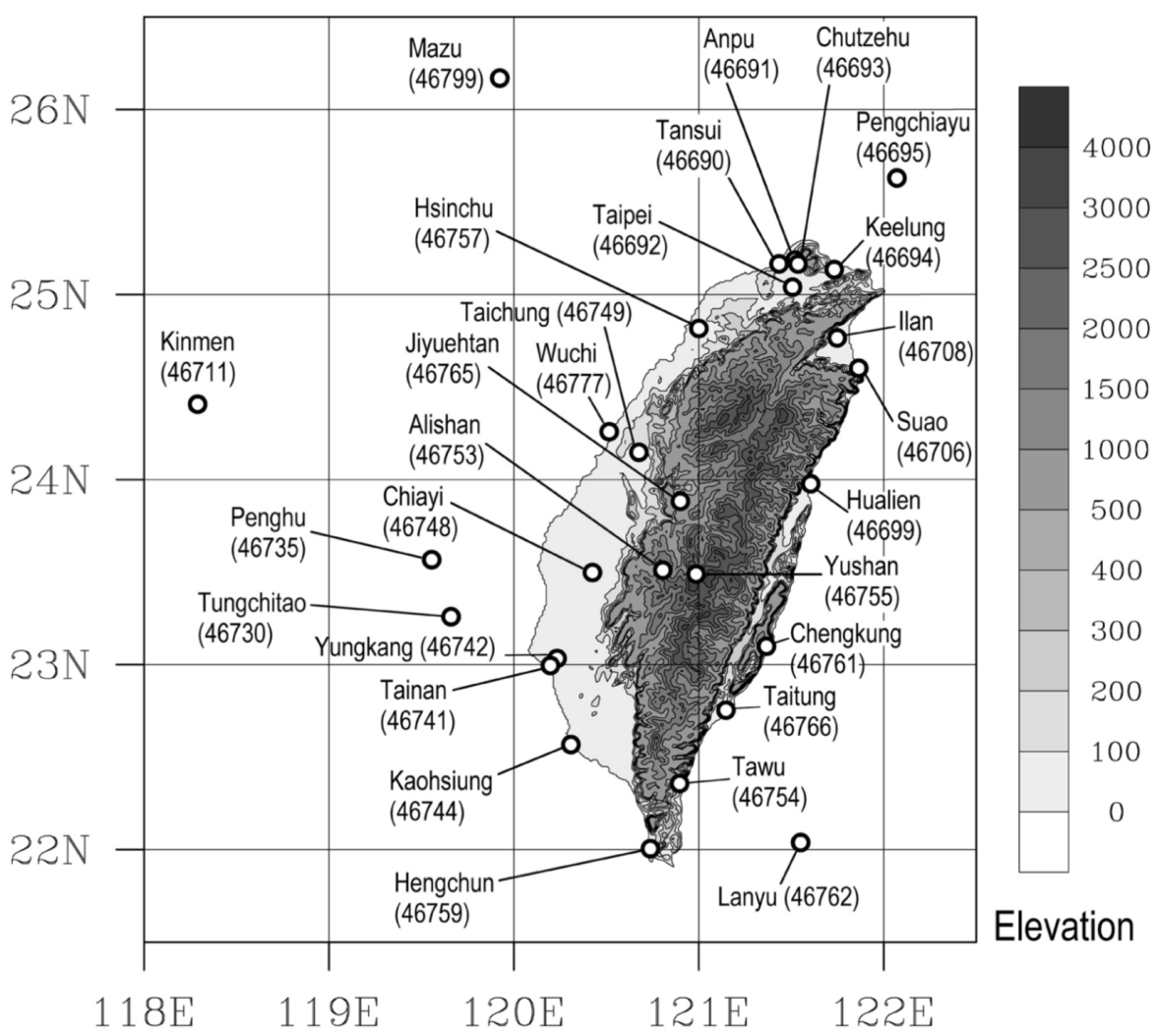

Fig. 1. The locations of CWB weather stations. The names used here are from CWB documents and the numbers provided are the 5-digit station codes. The unit for elevation is $\mathrm{m}$. 
Table 1. The revised information for stations without significant relocation in their history. The traditional 5-digit station codes along with one extra code are listed for data users. The dates are provided when they are available. For some unclear records, only the year or the year with month is provided.

\begin{tabular}{clcll}
\hline Station code & Station name & $\begin{array}{c}\text { Year of } \\
\text { Commencement }\end{array}$ & $\begin{array}{c}\text { Beginning time of } \\
\text { observation }\end{array}$ & $\begin{array}{c}\text { Beginning time of the present } \\
\text { observational location }\end{array}$ \\
\hline $46695-0$ & Pengchiayu & 1936 & 1910 (by lighthouse) & 1936 \\
$46753-0$ & Alishan & 1933 & 1933.03 .15 & 1933.03 .15 \\
$46691-0$ & Anpu & 1943 & 1943.01 .01 & 1943 \\
$46761-0$ & Chengkung & 1940 & 1940.01 .01 & 1940.01 .01 \\
$46748-0$ & Chiayi & 1968 & 1968.09 .01 & 1968.09 .01 \\
$46693-0$ & Chutzehu & 1943 & 1943.01 .01 & 1943 \\
$46759-0$ & Hengchun & 1896 & 1896.11 .20 & 1905.12 .25 \\
$46699-0$ & Hualien & 1921 & 1910.10 (by lighthouse) & 1921.09 .01 \\
$46708-0$ & Ilan & 1935 & 1936.01 .01 & 1936.03 .12 \\
$46765-0$ & Jiyuehtan & 1941 & 1941 & 1941 (wind) \\
& & & & 1951.12 (other variables) \\
$46711-0$ & Kinmen & 2004 & 2004.01 & 2004.01 \\
$46762-0$ & Lanyu & 1939 & 1941.11 .01 & 1941.11 .01 \\
$46799-0$ & Mazu & 2003 & 2004.01 .01 & 1898.01 .01 \\
$46735-0$ & Penghu & 1896 & 1896.11 .21 & 1981 \\
$46706-0$ & Suao & 1981 & 1981 & 1901.10 .01 \\
$46766-0$ & Taitung & 1900 & 1901.01 .01 & 1942 \\
$46690-0$ & Tanshui & 1942 & 1942 & 1940.01 .01 \\
$46754-0$ & Tawu & 1940 & 1940.01 .01 & 1962.10 \\
$46730-0$ & Tungchitao & 1962 & 1962.10 & 1976 \\
$46777-0$ & Wuchi & 1976 & 1976 & 1943.08 \\
$46755-0$ & Yushan & 1943 & 1943.08 & \\
\hline
\end{tabular}

Table 2. Similar to Table 1, but for the revised information of stations with significant relocation in their history. The shaded and un-shaded zones here are used to separate the different groups of station records, which are discussed in the text. The order of groups follows the text in section 3.

\begin{tabular}{|c|c|c|c|c|c|}
\hline Station code & Station name & $\begin{array}{c}\text { Year of } \\
\text { commencement }\end{array}$ & $\begin{array}{c}\text { Beginning time of } \\
\text { observation }\end{array}$ & $\begin{array}{c}\text { Ending time of } \\
\text { tentative observation }\end{array}$ & $\begin{array}{l}\text { Ending time of } \\
\text { the observation }\end{array}$ \\
\hline $46744-0$ & Kaohsiung (old harbor) & 1931 & 1931.04 .01 & ---- & 1973.04 .30 \\
\hline 46744-0 & Kaohsiung (Chian-jen) & ---- & 1973.05 .01 & ---- & ---- \\
\hline $46694-0$ & Keelung & 1946 & $\begin{array}{l}1901.07 \\
\text { (by lighthouse) }\end{array}$ & 1973.01 .01 & ---- \\
\hline $46757-0$ & Hsinchu (Hsinchu city) & 1938 & 1937 & 1938.01 .01 & 1994.07.31 \\
\hline $46757-1$ & Hsinchu (Chu-pei city) & 1991 & 1991.07.01 & ---- & ---- \\
\hline 46749-0 & Taichung (old location) & 1896 & 1896.12 .20 & 1901.05 .20 & 1954.03 .31 \\
\hline 46749-0 & Taichung (new location) & --- & 1954.04 .01 & ---- & ---- \\
\hline $46692-0$ & Taipei & 1896 & 1896.08 .11 & 1897.12 .19 & 1992.01 .31 \\
\hline $46692-1$ & Taipei (TMTC) & 1992 & 1992.02 .01 & ---- & 1997.08.31 \\
\hline $46692-0$ & Taipei & ----- & 1997.09.01 & ---- & ---- \\
\hline $46741-0$ & Tainan & 1897 & 1897.01 .01 & 1898.03 .03 & 1998.04 .30 \\
\hline $46741-1$ & Tainan (Yungkang) & 1996 & 1996.01.01 & ---- & 2001.12 .31 \\
\hline $46741-0$ & Tainan & --- & 2002.01 .01 & --- & ---- \\
\hline $46742-0$ & Yungkang & 1940 & 1940 & ---- & 1974.12.31 \\
\hline $46742-0$ & Yungkang & --- & 1998.05 .01 & ---- & ---- \\
\hline
\end{tabular}


suburb of Taipei. The distance between meteorological observatories in Taipei and Tansui is about $16 \mathrm{~km}$. Although weather observations at Tanshui can be traced back to the Ching Dynasty and Tanshui lighthouse workers conducted meteorological observation during the early JP era, the Tanshui station was officially established in 1942 for Tanshui's seaplane airport. The observational location of the Tanshui station has remained the same since its official commencement in 1942; however, a strange temperature deviations has been found between Tanshui and Taipei during the 1980s. As seen in Fig. 2, the annual mean temperature of Tanshui is almost the same as that of Taipei (No. 46692) before the early 1980s. After 1983, however, Tanshui's temperature suddenly declined. And although Taipei's temperature between 1992 - 1997 shows an anomalous decrease owing to a tentative relocation of the Taipei station due to renovations (next section), the $1^{\circ} \mathrm{C}$ difference after 1983 between Tanshui and Taipei is quite peculiar. Further analysis shows that this unusual cooling is found mostly at Tmin $\left(\sim 2^{\circ} \mathrm{C}\right.$ over 3 years) for Tanshui.

Daytime urban warming is reported less than nighttime temperature increases for cities (Gallo and Owen 1999). This can explain the large increase in Tmin with relatively small increases in Tmax for urban areas. To adjust urban warming to accommodate long-term temperature trends, Legg's (1989) method makes adjustment for Tmin only and no change for Tmax. Parker and Horton (2005), on the other hand, propose a weighting reassignment of $75 \%$ for Tmin and $25 \%$ for Tmax. Such different considerations for Tmax and Tmin are typical of adjustment methods for accommodating urban warming trends. The time series for Tanshui and Taipei exhibit similar warming for urban Tmin (or cooling for suburban Tmin), but no significant difference exists for Tmax. However, this sudden increase in temperature deviation for Tmin between Taipei and Tanshui of $2^{\circ} \mathrm{C}$ over 3 years is still strange as other suburban stations near Taipei such as Anpu (No. 46691) and Chutzehu (No. 46691) do not have similar temperature deviations. As there is no record of change in the observational location of the Tanshui station since 1942, further explanation of possible factors contributing to this strange temperature deviation is needed. One possibility is the Tanshui station becoming an automated weather station in the 1980s (section 4). This may have affected the accuracy of data and caused such temperature deviations. However, we will not know the answer to this until the CWB reviews the instrumentation history of this meteorological observatory.

\section{STATIONS WITH SIGNIFICANT RELOCATIONS}

In addition to the stations discussed previously, several CWB meteorological observatories have been permanently moved or tentatively relocated. Changes relating to these stations have significantly affected their data characteristics in long-term climate description and require homogeneity adjustments. Information relating to these stations is summarized in Table 2.

\subsection{Stations with Permanent Relocations}

\subsubsection{Kaohsiung (No. 46744)}

Kaohsiung was once known as Takao in the JP era. Meteorological observations began here in the Ching Dynasty and there are some surviving records from between 1888 and 1894. During the JP era, Takao lighthouse commenced weather observations from March 1898, while the official meteorological observatory was established on 1 April 1931 atop Takao Mountain in the old harbor area. Because a new harbor was built in Chian-jen area during the 1960s and 70 s, Kaohsiung weather station was moved to its present location at Chian-jen harbor on 1 May 1973. The effect of the new environment into which this station was relocated produced extensive changes to basic meteorological characteristics in Kaohsiung's weather records. The original location was atop a hill facing the sea (Taiwan Strait), while the new location is in the harbor surrounded by warehouses. Rainfall characteristics differ between these two locations according to experienced local weather observers and the connection between other meteorological variables for the two Kaohsiung stations are yet to be established.

In order to establish whether an artificial abrupt change occurred here due to station relocation, long Hengchun (46759) data is used for comparison purposes. As indicated in Table 1, the Hengchun station has not been moved since 25 December 1905 except for the WWII period. The annual temperature (hereafter T), Tmax and Tmin time series of both stations are shown in Fig. 3, which indicates the annual $\mathrm{T}$ for both stations being almost the same before 1948 and after 1979. However, the annual T of Hengchun is significantly lower than that of Kaohsiung from 1948 to 1979. Note: the Kaohsiung station was relocated in May 1973. Therefore, there is no apparent reason for such a deviation simply because of station relocation at Kaohsiung. This comparison suggests that the noted temperature changes between these three sites involve factors other than simply station location. These factors will be addressed in the discussion section.

\subsubsection{Keelung (No. 46694)}

Keelung station commenced observations in 1946 (Table 1). However, observation data exists for Keelung since the Ching Dynasty. During the JP era, the construction bureau for Keelung harbor established a meteorological observatory in the late $19^{\text {th }}$ century. This station was closed in April 1916. Keelung lighthouse began its own observations in July 1901. The official commencement of the Keelung station by the CWB was in 1946 after WWII. Data before this 

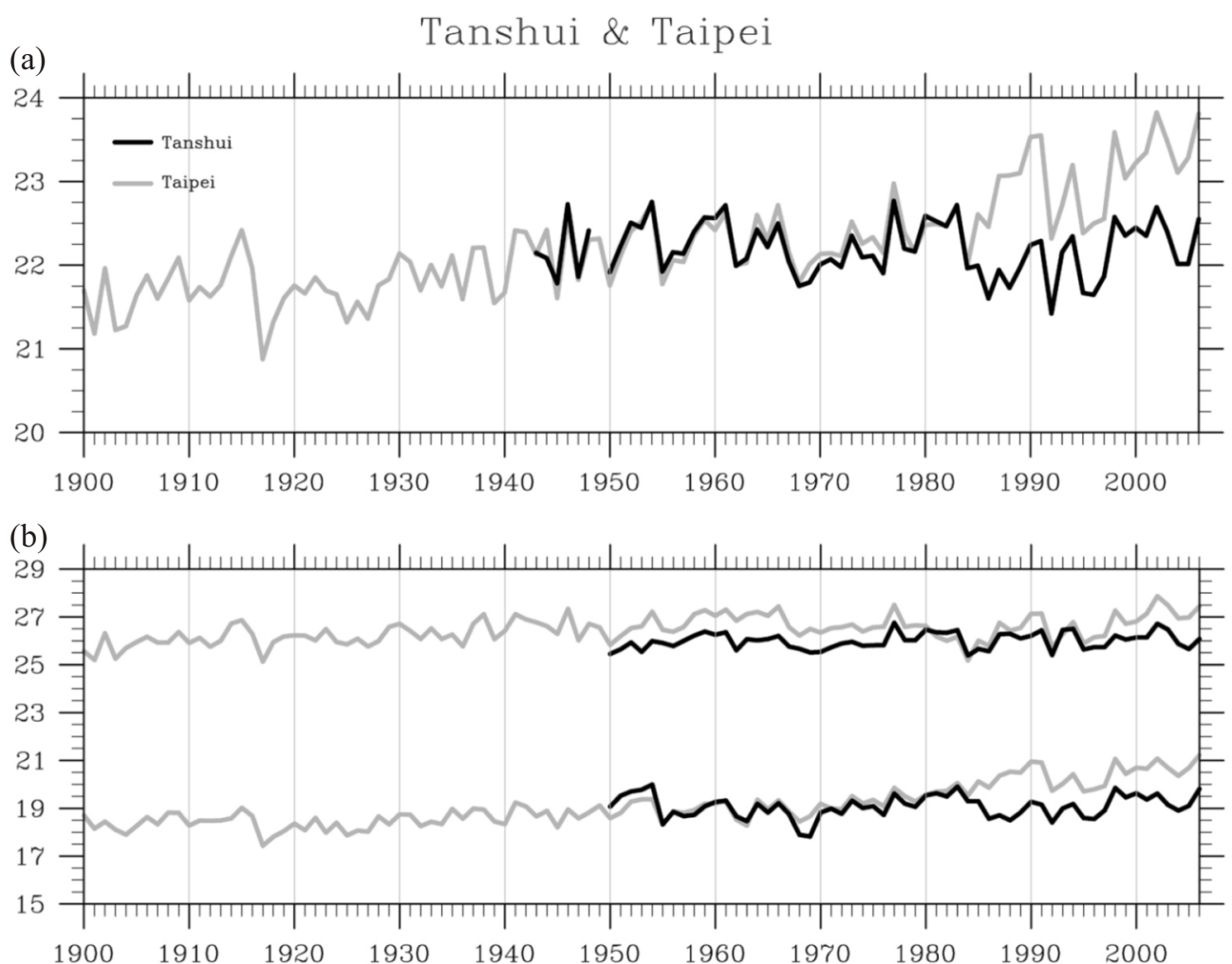

Fig. 2. (a) The annual temperature values of Tanshui (black line) and Taipei (gray line). (b) The annual Tmax and Tmin values of Tanshui (black line) and Taipei (gray line). The upper and lower time series are for Tmax and Tmin, respectively. The unit for T, Tmax, and Tmin is ${ }^{\circ} \mathrm{C}$.
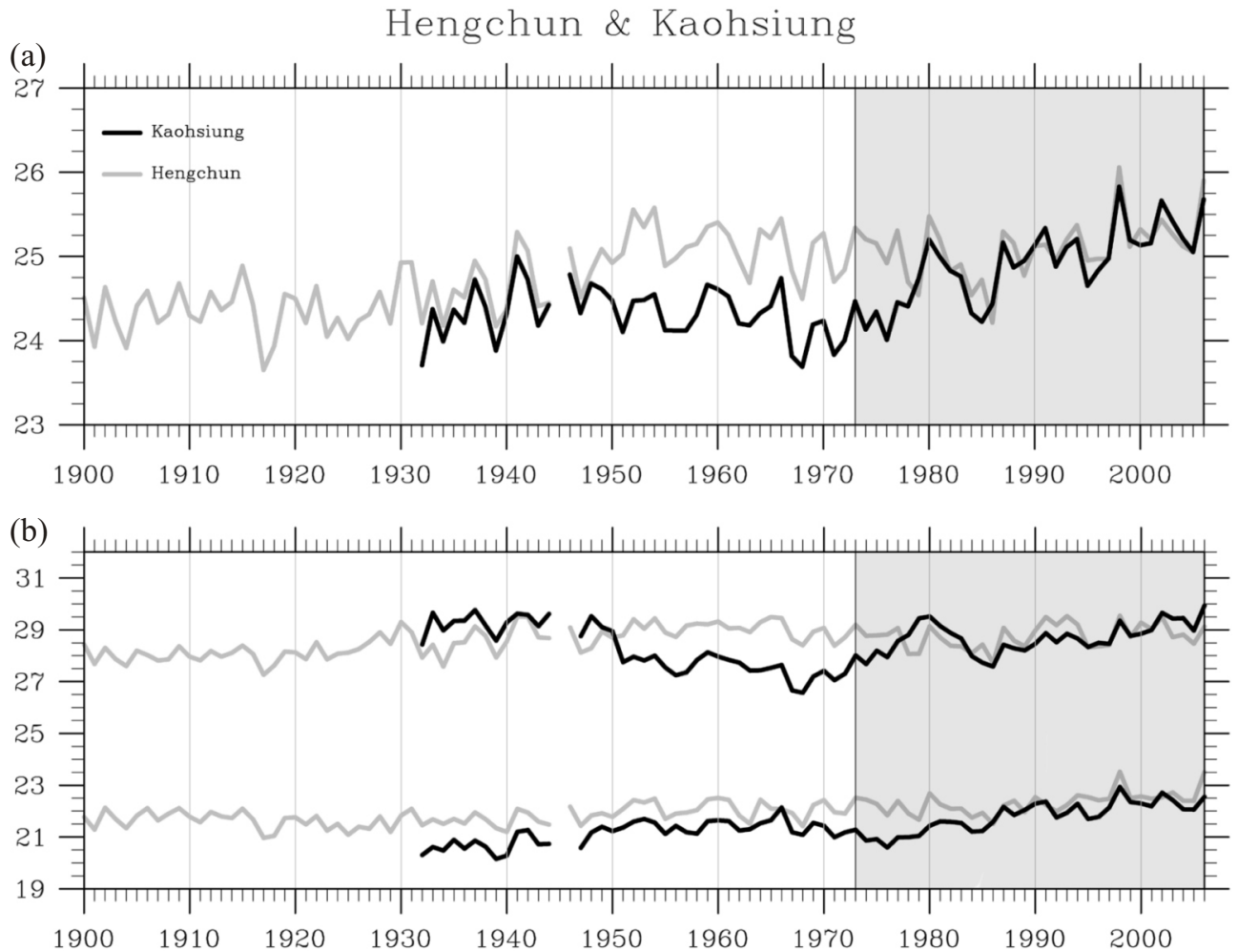

Fig. 3. (a) The annual temperature values of Kaohsiung (black line) and Hengchun (gray line). (b) The annual Tmax and Tmin values of Kaohsiung (black line) and Hengchun (gray line). The upper and lower time series are for Tmax and Tmin, respectively. The period with shading indicates the new observational site of Kaohsiung station in Chian-jen harbor. The unit for T, Tmax, and Tmin is ${ }^{\circ} \mathrm{C}$. 
period quite possibly comes from the Keelung lighthouse. In addition, observational locations at Keelung have changed several times, even after WWII. Complicating the situation at Keelung is that the wind tower, observational yard (for temperature, precipitation, and most variables) and the office were at different locations on the eastern and western sides of the harbor [these complicated observational locations for Keelung are summarized in Hung (2007)]. It is suggested that interested researchers not apply Keelung data prior to 1 January 1973 to long-term interdecadal studies. After this date, however, data is reliable as it was all collected at the present Keelung station atop the Keelung harbor building.

\subsubsection{Hsinchu (No. 46757)}

Hsinchu station was established in the JP era after a serious earthquake in 1935. Tentative observations began in mid 1937 when the meteorological observatory was under construction. Official observations began on 1 January 1938, while the commencement date for this station is 20 June 1938. Because observational instruments at the original Hsinchu station were influenced by a radio station nearby, the CWB finally decided to move the Hsinchu station to Chu-pei city, a suburban area north of Hsinchu city. Weather observations were officially transferred to the new site on 1 July 1991 . However, observations from the old station continued until 31 July 1994. Interested users can distinguish records from both observational locations in the CWB database by the station codes. The original Hsinchu station is listed as 46757-0 and the new Hsinchu station in Chu-pei city is 46757-1. Because of several overlapping years between the new and old Hsinchu stations, T, Tmax, and Tmin from these two sites can be compared during this period. The annual $\mathrm{T}$ and Tmin from Hsinchu observed in the old site are slightly lower than those of the new site, while Tmax over at the old site is slightly higher than that of the new site (not shown). Therefore, Hsinchu data requires further testing to examine possible biases due to this relocation.

\subsubsection{Taichung (No. 46749)}

Taichung station is one of five very early meteorological observatories established in the JP era during the late $19^{\text {th }}$ century. The commencement date for the Taichung station is 20 December 1896. Tentative observational locations were used initially, but the observational location remained the same from 20 May 1901 until March 1954 when the Taichung station was moved to its present location due to urban planning. Data collection commenced on 1 April 1954 at the new location, Taichung Park. Because distance between old and new sites is small, interested users could possibly combine data for these two observational sites. However, testing for homogeneity of the Taichung data is still suggested.

\subsection{Stations with Tentative Relocation}

\subsubsection{Taipei (No. 46692)}

Taipei station was established on 11 August 1896. A tentative observation location for Taipei city was used initially, and a permanent station was established on 19 December 1897 when the meteorological observatory was built at its present location. Although the office buildings have been re-built several times, Taipei station has remained on almost the same block except for recent construction between 1 February 1992 and 31 August 1997. During this period, observation was tentatively moved to the Taipei Municipal Teachers' College (TMTC, currently renamed as Taipei Municipal University of Education), which is only several hundred meters from the CWB. However, data during this construction period is unexpectedly low. Using temperature observations from Song-shan airport (northern Taipei) to compare with Taipei data at the TMTC site, this unexpected lower temperature is clearly evident (Fig. 4).

Weather observations at Song-shan airport are by the runway meaning there is less urban effect. Overall, the annual mean temperature at Song-shan airport is lower than that at Taipei station (Fig. 4a). However, during the construction period of the Taipei station (the shaded years in Fig. 4a), Taipei's temperature observed at the TMTC is lower than that at Song-shan airport. After August 1997 when the observational location moved back to the front gate of the CWB, both temperature records returned to their previous relationship. Because Song-shan airport does not provide daily Tmax and Tmin data, equivalent Tmax and Tmin derived from daily hourly maximum and minimum temperature values are used to compare Tmax and Tmin at Taipei. In Fig. 4b, equivalent Tmax and Tmin at Song-shan airport are almost the same as or lower than those of Taipei except during the construction period. After August 1997, both Tmin values remain the same, while the annual mean of Tmax at Song-shan airport is still lower than that in Taipei. Above results have been checked with seasonal and monthly values, and similar results can be found (not shown). Therefore, interested data users should take care in combining Taipei data during this construction period (1 February 1992 and 31 August 1997). The unexpectedly lower temperature in Taipei during this time may be due to the environment at the tentative observational location of the TMTC with trees and buildings very close by. Homogeneity adjustment for Taipei data during this tentative relocation period is strongly recommended.

\subsubsection{Tainan (No. 46741)}

Tainan is one of the oldest stations built in the early JP era. It commenced on 1 January 1897. A tentative observation location was used initially; however, the present location has remained the same since 3 March 1898 except for 
recent reconstruction at the site from 1998 to 2001. The situation in Tainan was very similar to that of the Taipei station when it was being renovated. Observation in Tainan, however, were totally moved to Yungkang, a suburb north of Tainan. Yungkang station was at the ex-Tainan civil airport in the JP era. Commencement data at Yungkang, then known as the Tainan airport branch office, can be traced back to January 1940. After WWII, this station was renamed Yungkang and took daily observations until December 1974 when it was closed. The CWB planned to move all of Tainan's staff tentatively to Yungkang to continue their observation work whilst the Southern Region Weather Center (Tainan station) was under construction, a new building at Yungkang station was built and observations re-started on 1 January 1996. Yungkang replaced Tainan station observations for the period 1 May 1998 to 31 December 2001.

Interested users should note that the station number 46741-0 refers to observational data for Tainan's original site since 1898. Its data ended on 30 April 1998 and restarted on 1 January 2002. Yungkang station was known as 46742 or 46742-0 in the database before 31 December 1974 and after 1 May 1998. The 46741-1 is the tentative Tainan station and its data is for 1 January 1996 to 31 December 2001. Therefore, data for 46741-1 and 46742-0 between 1 May 1998 and 31 December 2001 are exactly the same. Users need only consider observations at Yungkang ending on 31 December 1974 and re-starting from 1 January 1996, while observations at the present Tainan station discontinued on 30 April 1998 and re-started from 1 January 2002.

Although observation at Yungkang discontinued between 1975 and 1995, there are many surviving records that can be used for homogeneity adjustments for Tainan's data. It is clearly evident that the annual mean temperature of Yungkang is always lower than that of Tainan by about $0.5^{\circ} \mathrm{C}$ (Fig. 5). This cooler temperature at Yungkang is found in the summer and significantly in Tmin (not shown). This apparent difference in temperatures between Yungkang and Tainan stations means that it would be better for interested users not to simply combine Yungkang data with that of Tainan during the construction period without homogeneity adjustment. Another important note for Tainan data users is that the new observational location of the Tainan station (Southern Region Weather Center of the CWB) starting from 1 January 2002 is atop the new building. Altitude is now $40.791 \mathrm{~m}$ compared a previous $13.8 \mathrm{~m}$ (before 1998). Biases can be expected due to this altitude change.

\section{CONCLUSIONS AND DISCUSSION}

Homogeneity adjustments are necessary for in situ data to be used in climate research (Peterson et al. 1998). Detailed descriptions of station history are important reference tools for data adjustment. Unfortunately, no homogeneity adjustments of climate data in Taiwan or detailed historical background checks of stations have been conducted previously. This study does the preliminary work for future researchers to do their homogeneity adjustments. Relocation records of weather stations in Taiwan are summarized in Tables 1 and 2. Relocation times listed in these tables can be used for checking artificially abrupt changes in time series data. In addition, this study notes anomalous temperature deviations between Tanshui and Taipei since the early 1980s and in Kaohsiung and Hengchun between 1948 and 1979. These unusual temperature deviations have largely shifted interannual variation by $1^{\circ} \mathrm{C}$ or more during these periods. The reasons are unknown but require further study before these data are ready for further analysis. Other relocation problems due to station reconstruction periods are also discussed. Data from Taipei and Tainan are long enough for interdecadal analysis, but the reconstruction periods at stations in recent years have disrupted the long-time series data. If interested users simply combine data for Yungkang and Tainan or for the tentative observational location at TMTC for Taipei without any homogeneity adjustments, real temperature variations will be replaced by lower temperature values that do not truly reflect real climate characteristics.

In addition to station relocation issues, observational schedules (observational time and frequency) are important when hourly data have to be averaged into the daily means (Peterson et al. 1998). During earlier observation periods at many stations in Taiwan, weather observers did the observation only 6 times a day. For example, when the 5 earliest stations (Taipei, Taichung, Tainan, Hengchun, and Penghu) were established in $1896 \sim 1897$, only Taipei station did hourly observations, while the other 4 stations conducted observations at: $0200,0600,1000,1400,1800$, and $2200 \mathrm{LT}$; "LT" is "local time". For most stations during WWII, observations were conducted at: 0600,1400 , and 2200 LT only. Although present CWB standard process requires daily temperature to be averaged from hourly numbers, it still remains unknown how station workers averaged local-time data into daily mean temperatures for WWII and earlier. For some stations, there were no nighttime observations (i.e., between 2200 and 0600 LT). It is possible that daily values are biased toward daytime observations. In terms of warming, a lack of nighttime observations may cause unexpected cooling during this period when nighttime observations were not added to observational schedules. To avoid artificial cooling due to different observational schedules, use of daily maximum and minimum temperatures is suggested rather than daily mean temperature. An empirical model for estimating time of observation bias associated with different observational schedules is provided by Karl et al. (1986). Note: this model was developed for monthly mean temperature, Tmax and Tmin in the United States. Nevertheless, a similar method could be applied to Taiwan's data if necessary.

Instrumentation change is another factor contributing to artificially pronounced discontinuities in time series from in 

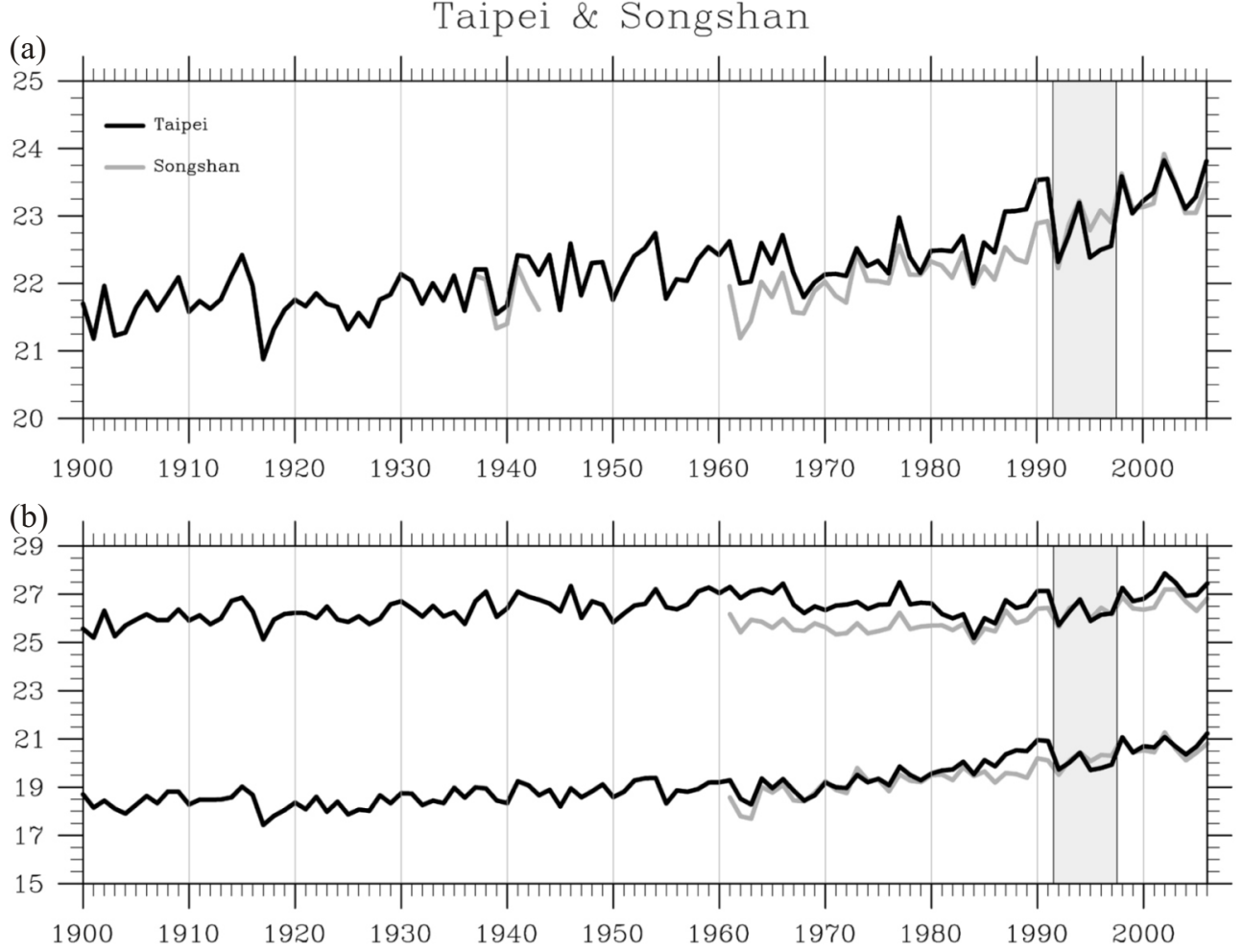

Fig. 4. (a) The annual temperature values of Taipei (black line) and Song-shan airport (gray line). (b) The annual Tmax and Tmin values of Taipei (black line) and Song-shan airport (gray line). The upper and lower time series are for Tmax and Tmin, respectively. The shading indicates the reconstruction period of Taipei station, and tentative observations made in the TMTC. The unit for T, Tmax, and $\mathrm{Tmin}^{\circ}{ }^{\circ} \mathrm{C}$.
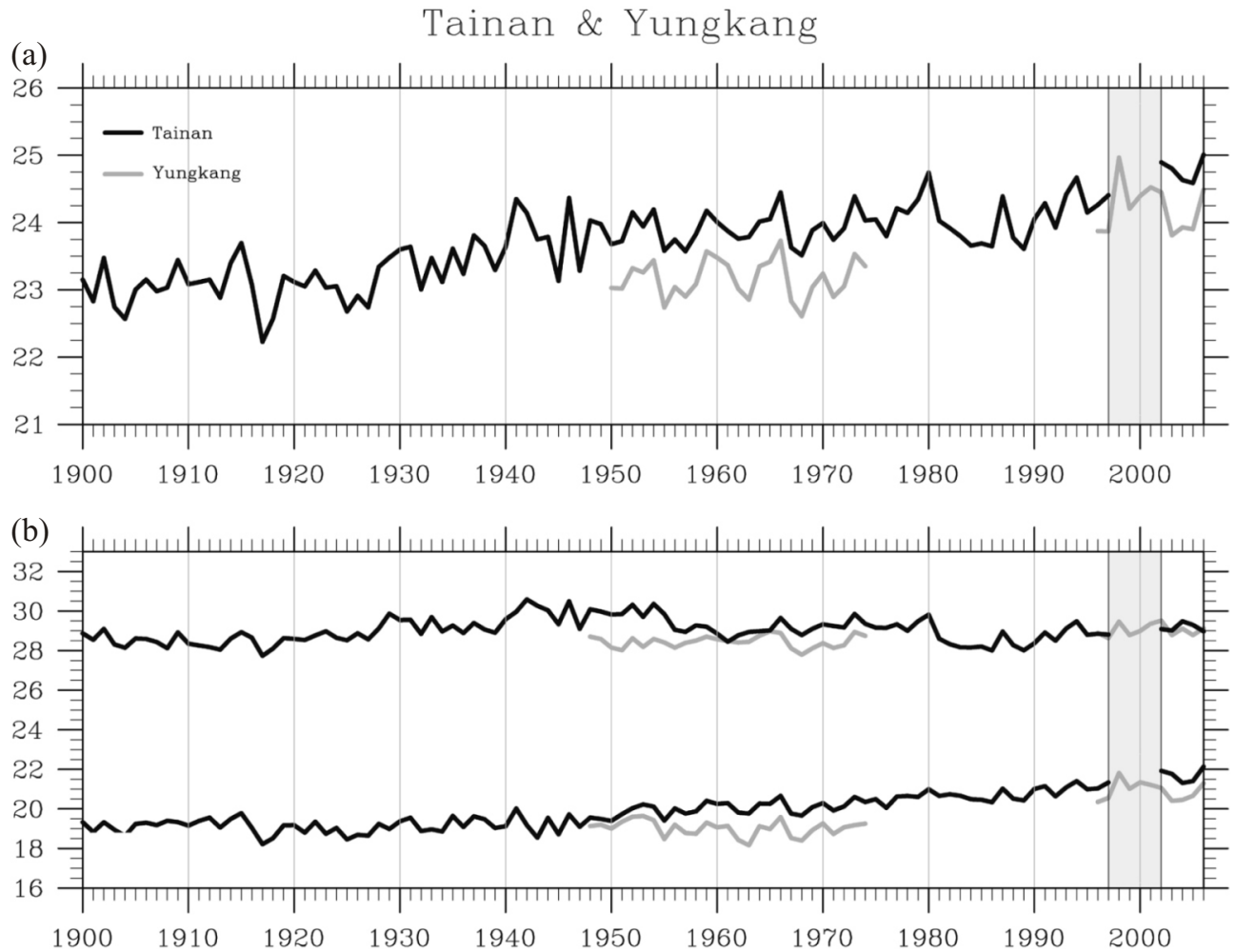

Fig. 5. (a) The annual temperature values of Tainan (black line) and Yungkang (gray line). (b) The annual Tmax and Tmin values of Tainan (black line) and Yungkang (gray line). The upper and lower time series are for Tmax and Tmin, respectively. The shading indicates the reconstruction period of Tainan station. The unit for T, Tmax, and Tmin is ${ }^{\circ} \mathrm{C}$. 
situ data. Appropriate adjustment is required before data is used for further interpretation. To adjust for a lack of homogeneity in data caused by instrument changes, a well-documented history of such changes is very important and necessary. For example, Nicholls et al. (1996) detailed records for historical thermometer exposures in Australia, while Parker (1994) has a comprehensive survey for the effects of changing the exposure of thermometers worldwide. Climate data in Taiwan has been adjusted by some individual studies regarding changes to instrumentation. For example, Liu et al. (2002) studied reduction in sunshine duration over Taiwan. In their analysis, it is necessary to adjust values when the use of the Compbell-Stokes instrument changed to the Jordin type instrument. However, no official adjusted datasets have been provided by the CWB regarding changes of instruments, and several variables lack homogeneity. As noted by Chen (1997), pressure data in Taiwan lacks homogeneity due to instrumentation problems. Chen (1997) recorded that mercury in a barometer had not been cleaned for more than 25 years since 1945 when Japan ended their occupation in Taiwan. This means that pressure data is not reliable before careful calibration in 1971. Another concern regarding instrumentation and its influence on data is automated observational systems installed during the 1980s for every station in Taiwan. As described in Chen (1997), the testing mode of this system was during 1983 - 1986, and most stations officially began to use this system in 1987. Although the automated observational system highly increases the quality of data and observational frequency, differences in data quality may result in artificially sharp discontinuities. For those stations completely automated, there are no observers to calibrate instruments on a daily basis (for example, Tanshui and Yungkang); this could lead to sudden changes in climate characteristics (e.g., Fig. 2).

Because maintaining weather stations over very long periods is difficult, homogeneity adjustments are useful for improving climate data. Side-by-side comparisons of instruments for documented changes are commonly applied in many countries to adjust data (Peterson et al. 1998). A sideby-side comparison of instruments over a long period, at least for a full year or a decade, is the best reference for data adjustment. Nicholls et al. (1996) indicated that side-by-side comparisons of the temperature measured in a Glaisher stand and Stevenson screen were made in Adelaide, Australia for a period of more than 60 years since the late $19^{\text {th }}$ century. However, such long-term side-by-side comparisons are not available in too many places around the world, including Taiwan.

There are statistical methods to detect undocumented change points for station relocations and instrument replacements (Easterling and Peterson 1995; Menne and Williams 2005). However, a well-documented history of stations is the best reference for users to do homogeneity adjustments. Although there is no homogeneous adjusted dataset for Taiwan provided in this preliminary work, the summarized information regarding station relocations can help data users check for artificially abrupt changes that might not reflect the true character of the weather and climate of Taiwan. With these important reviews of station history, it is possible to do homogeneity adjustments of in situ climate data in Taiwan.

Acknowledgements The author thanks two reviewers for their useful comments on the manuscript. The suggestions from H. H. Hsu, Y. L. Chen, and M. D. Chou are especially appreciated. Special thanks are extended to Y. M. Li for his help in figure preparation. This work was supported by the National Science Council under grants NSC 96-2111M-034-002 and NSC 97-2111-M-003-004-MY2.

\section{REFERENCES}

Chen, F. L., 1997: The history of the surface and atmosphere observations and their associated instruments in Taiwan for the past one hundred year. Bull. Meteorol. Soc. China, 38, 5-25. (in Chinese)

CWB (Central Weather Bureau), 2002: Summary report of meteorological data (Taiwan), Volume VI 1991 2000, published by the Central Weather Bureau, $515 \mathrm{pp}$.

Easterling, D. R. and T. C. Peterson, 1995: A new method for detecting undocumented discontinuities in climatological time series. Int. J. Climatol., 15, 369-377, doi: 10.1002/ joc.3370150403. [Link]

Gallo, K. P. and T. W. Owen, 1999: Satellite-based adjustments for the urban heat island temperature bias. J. Appl. Meteorol., 38, 806-813, doi: 10.1175/1520-0450(1999)038 $<0806$ :SBAFTU $>2.0$. CO;2. [Link]

Hung, C.-w., 2007: The History of Meteorological Observatories in Taiwan, Taiwan Interminds Publishing Inc., 293 pp. (in Chinese)

Karl, T. R. and C. N. Williams, Jr., 1987: An approach to adjusting climatological time series for discontinuous inhomogeneities. J. Climate Appl. Meteorol., 26, 1744-1763, doi: 10.1175/1520-0450(1987)026<1744:AATACT>2.0.CO;2. [Link]

Karl, T. R., C. N. Williams, Jr., P. J. Young, and W. M. Wendland, 1986: A model to estimate the time of observation bias associated with monthly mean maximum, minimum, and mean temperature for the United States. J. Climate Appl. Meteorol., 25, 145-160, doi: 10.1175/15200450(1986)025<0145:AMTETT>2.0.CO;2. [Link]

Legg, T. P., 1989: Removal of Urbanisation Effects from the Central England Temperature Data-Sets (Long-Range Forecasting and Climate Memorandum), Hadley Centre, Published by the Meteorological Office, Exeter, UK.

Liu, S. C., C. H. Wang, C. J. Shiu, H. W. Chang, C. K. Hsiao, and S. H. Liaw, 2002: Reduction in sunshine duration over Taiwan: Causes and implications. Terr. Atmos. Ocean. Sci., 13, 523-545. 
Menne, M. J. and C. N. Williams, Jr., 2005: Detection of undocumented changepoints using multiple test statistics and composite reference series. J. Climate, 18, 4271-4286, doi: 10.1175/JCLI3524.1. [Link]

Menne, M. J. and C. N. Williams, Jr., 2009: Homogenization of temperature series via pairwise comparisons. J. Climate, 22, 1700-1717, doi: 10.1175/2008JCLI2263.1. [Link]

Nicholls, N., R. Tapp, K. Burrows, and D. Richards, 1996: Historical thermometer exposures in Australia. Int. J. Climatol., 16, 705-710, doi:10.1002/(SICI)1097-0088(199606) 16:6<705::AID-JOC30>3.0.CO;2-S. [Link]

Parker, D. E., 1994: Effects of changing exposure of thermometers at land stations. Int. J. Climatol., 14, 1-31, doi: 10.1002/joc.3370140102. [Link]

Parker, D. E. and E. B. Horton, 2005: Uncertainties in central England temperature 1878-2003 and some improvements to the maximum and minimum series. Int. J. Climatol., 25, 1173-1188, doi: 10.1002/joc.1190. [Link]

Peterson, T. C., D. R. Easterling, T. R. Karl, P. Groisman, N. Nicholls, N. Plummer, S. Torok, I. Auer, R. Boehm, D. Gullett, L. Vincent, R. Heino, H. Tuomenvirta, O. Mestre, T. Szentimrey, J. Salinger, E. J. Førland, I. H.-Bauer, H. Alexandersson, P. Jones, and D. Parker,1998: Homogeneity adjustments of in situ atmospheric climate data: A review. Int. J. Climatol., 18, 1493-1517, doi: 10.1002/(SICI) 1097-0088(19981115)18:13<1493::AID-JOC329>3.0. CO;2-T. [Link]

Quayle, R. G., D. R. Easterling, T. R. Karl, and P. Y. Hughes, 1991: Effects of recent thermometer changes in the cooperative station network. Bull. Am. Meteorol. Soc., 72, 1718-1723, doi: 10.1175/1520-0477(1991)072<1718: EORTCI $>2.0 . \mathrm{CO} ; 2$. [Link] 